\title{
Development of ToSPACE for Pipe Wall Thinning Management in Nuclear Power Plants
}

\author{
Kyeong Mo Hwang1, Hun Yun¹, Hyeok Ki Seo', Geun Young Lee², Kyung Woo Kim² \\ ${ }^{1}$ Material Engineering Department, Gimcheon, Korea \\ ${ }^{2}$ ByN Company, Daejeon, Korea \\ Email: hkm@kepco-enc.com
}

How to cite this paper: Hwang, K.M., Yun, H., Seo, H.K., Lee, G.Y. and Kim, K.W. (2019) Development of ToSPACE for Pipe Wall Thinning Management in Nuclear Power Plants. World Journal of Nuclear Science and Technology, 9, 1-15. https://doi.org/10.4236/wjnst.2019.91001

Received: October 23, 2018

Accepted: December 18, 2018

Published: December 21, 2018

Copyright $\odot 2019$ by authors and Scientific Research Publishing Inc. This work is licensed under the Creative Commons Attribution International License (CC BY 4.0).

http://creativecommons.org/licenses/by/4.0/

\begin{abstract}
A number of piping components in the secondary system of nuclear power plants are exposed to aging mechanisms such as FAC (Flow-Accelerated Corrosion), cavitation, flashing, SPE (Solid Particle Erosion), LDIE (Liquid Droplet Impingement Erosion), etc. Those mechanisms may lead to thinning, leak, or rupture of the components. Due to the pipe ruptures caused by wall thinning in Surry unit 2 of USA in 1986 and in Mihama unit 3 of Japan in 1994, the pipe wall thinning management has emerged as one of the most important issues in nuclear power plants. To manage the pipe wall thinning in the secondary system, Korea has used a foreign program since 1996. As using the foreign country's program for long term, it was necessary to improve from the perspective of the users. Accordingly, KEPCO-E \& C has started to develop the 3D-based pipe wall thinning management program (ToSPACE, Total Solution for Piping And Component Engineering management) from eight years ago, and the development was successful. This paper describes the major functions included in ToSPACE program, such as 3D-based DB (Database) buildup, development of FAC and erosion evaluation theories, UT (Ultra-sonic Test) data reliability analysis, field connection with 3D, automatic establishment of long-term inspection plan, etc. ToSPACE program was developed to allow site engineers performing the selection of inspection quantity at each refueling outage, UT data reliability analysis, UT evaluation, determination of next inspection timing, identification of the inspecting and replacing components in $3 \mathrm{D}$ drawings, etc., to access easily.
\end{abstract}

\section{Keywords}

ToSPACE, Pipe Wall Thinning, Flow-Accelerated Corrosion (FAC), Liquid Droplet Impingement Erosion (LDIE), Reliability Analysis, 3D Management, Long-Term Inspection Plan 


\section{Introduction}

As operating time progresses, carbon steel piping components in the secondary system of nuclear power plants gradually get thinner resulting from aging mechanisms, such as FAC (Flow-Accelerated Corrosion), cavitation, flashing, LDIE (Liquid Droplet Impingement Erosion), and SPE (Solid Particle Erosion). These mechanisms induce the wall thinning of components and finally lead to components rupture [1] [2]. The damages are closely related to fluid such as water or wet steam inside the components. The notable events were the pipe ruptures in Surry unit 2 in 1986 and in Mihama unit 3 in 1994. Those events evoked several casualties and economic damage.

As of 2018, a total of 24 nuclear power plants are operating in Korea. The secondary side piping in the Korean nuclear power plants has also experienced the pipe wall thinning events and, as operating time increases, the events are expected to increase gradually. To manage the pipe wall thinning, there have been several programs for pipe wall thinning management so far such as CHECWORKS program of USA, BRT-CICERO program of France, and COMSY program of Germany. Korea has used the CHECWORKS program since 1996. However, a number of site engineers have advised to develop our own program considering the site applicability to get rid of the inconvenience of users. Accordingly, KEPCO-E\&C started to develop a 3D-based pipe wall thinning management program called ToSPACE (Total Solution for Piping And Component Engineering management) from 2013 after collecting opinions from site engineers and launched the program at the end of 2016. This paper describes major functions included in ToSPAEC, which are different from the existing foreign programs.

\section{Major Functions of ToSPACE}

\subsection{Introduction of ToSPACE}

ToSPACE is an engineering software for managing the wall thinning phenomenon that occurs in the piping of nuclear, fossil, and combined thermal power generation plants. It includes detailed functions for overall pipe wall thinning management such as susceptibility analysis for selecting target systems and lines, 3D modeling and DB buildup, wall thinning prediction, inspection data analysis, and establishment of long-term inspection plan. By using this program, it is possible to generate $\mathrm{DB}$ simultaneously with $3 \mathrm{D}$ modeling, and predict various thinning mechanisms, such as FAC, LDIE, SPE, cavitation, and flashing. Also, reliability analysis of a large number of inspection data is possible, and the next inspection timing reflecting the evaluation result of inspection data is automatically determined. The results of the prediction and inspection data evaluation are automatically fed back to long-term inspection plan. The major functions of ToSPACE are as follows:

- Management of plant operating information and design data

- Susceptibility analysis of systems and lines 
- DB buildup at the same time of 3D construction

- Water chemistry analysis for heat balance cycle

- Network analysis of pipelines

- Thermal hydraulic analysis

- Wall thinning analyses for FAC, LDIE, SPE, cavitation, and flashing

- Feedback of wall thinning prediction and inspected data evaluation results to susceptibility analysis

- Identification of the wall thinning prediction results on 3D

- Inspected data reliability analysis

- Wear and wear rate analysis using inspected data

- Calibration of wall thinning prediction results

- Identification of inspected and replaced locations on 3D

- Establishment of long term inspection plan

Subsequently, some of the key functions listed above are described in detail.

\subsection{Susceptibility Analysis}

Susceptibility analysis is the process of selecting systems and lines operated under conditions where wall thinning can occur in the entire plant systems and lines. The susceptibility analyses in ToSPACE are performed first for systems and then line susceptibility analysis is performed for the selected systems. Variables that are considered in the system susceptibility analysis include the safety related, personnel hazard, power generation, event experience, etc., and users can change the variables. Variables that are considered in the line susceptibility analysis include the fluid phase, event experience by aging mechanism, installation of orifices or control valves, noise of pipeline, operating temperature, flow velocity, dissolved oxygen, etc., and users can also add or delete the variables.

The susceptibility analysis in ToSPACE utilizes system and line list that are prepared at the stage of design. Once the form is extracted from the susceptibility analysis window of ToSPACE, the susceptible systems and lines are selected when selecting a list corresponding to the selection criteria and importing the form into ToSPACE. The wall thinning mechanism affecting the pipeline is unknown during susceptibility analysis, but once the wall thinning analysis, the subsequent module, has been performed, the results are fed back to determine the wall thinning mechanisms and the wear rate of the pipeline. Figure 1 shows an example of susceptibility analysis screen. In the figure, the left side is the system susceptibility analysis screen, and the right side is the line susceptibility analysis screen.

\subsection{D DB Construction}

To manage the pipe wall thinning, a component database of target systems and pipelines susceptible to thinning should be constructed. The number of target components that need to be managed per unit reaches 20,000, including the large and small bore piping, and the number of data to be entered in a program 
is about one million. Making this data to be a database takes a lot of time and effort, and there is a high possibility of human error caused by worker's mistake.

As a way to prevent these problems and facilitate user deployment of database, a 3D-based database-building method was developed and reflected in ToSPACE program. Figure 2 shows an example of a screen that builds a 3D-based database. Namely, once data such as pipe size, thickness, material, pressure, temperature, insulation information, etc. are entered at the starting point where the database is being built, the database is automatically created by connecting pipes on $3 \mathrm{D}$. This approach can reduce human error to a minimum level because users create a database while visually checking the shape of the piping layout. In addition, the installation location of the equipment such as steam generator, turbine, heater, pump, etc. may be placed in the same space coordinates as the site, and once the $3 \mathrm{D}$ model has been created, the entire pipeline group may be moved to another location.

\subsection{Thermal-Hydraulic Analysis}

Thermal-hydraulic analysis means the calculation of heat transfer and fluid flow behavior inside pipelines according to its layout shape, friction loss, and heat transfer characteristics. Although a number of programs are provided to calculate the thermal-hydraulics of fluid flow inside a pipeline, the calculation logic should be included within the program to perform the analysis with ToSPACE,

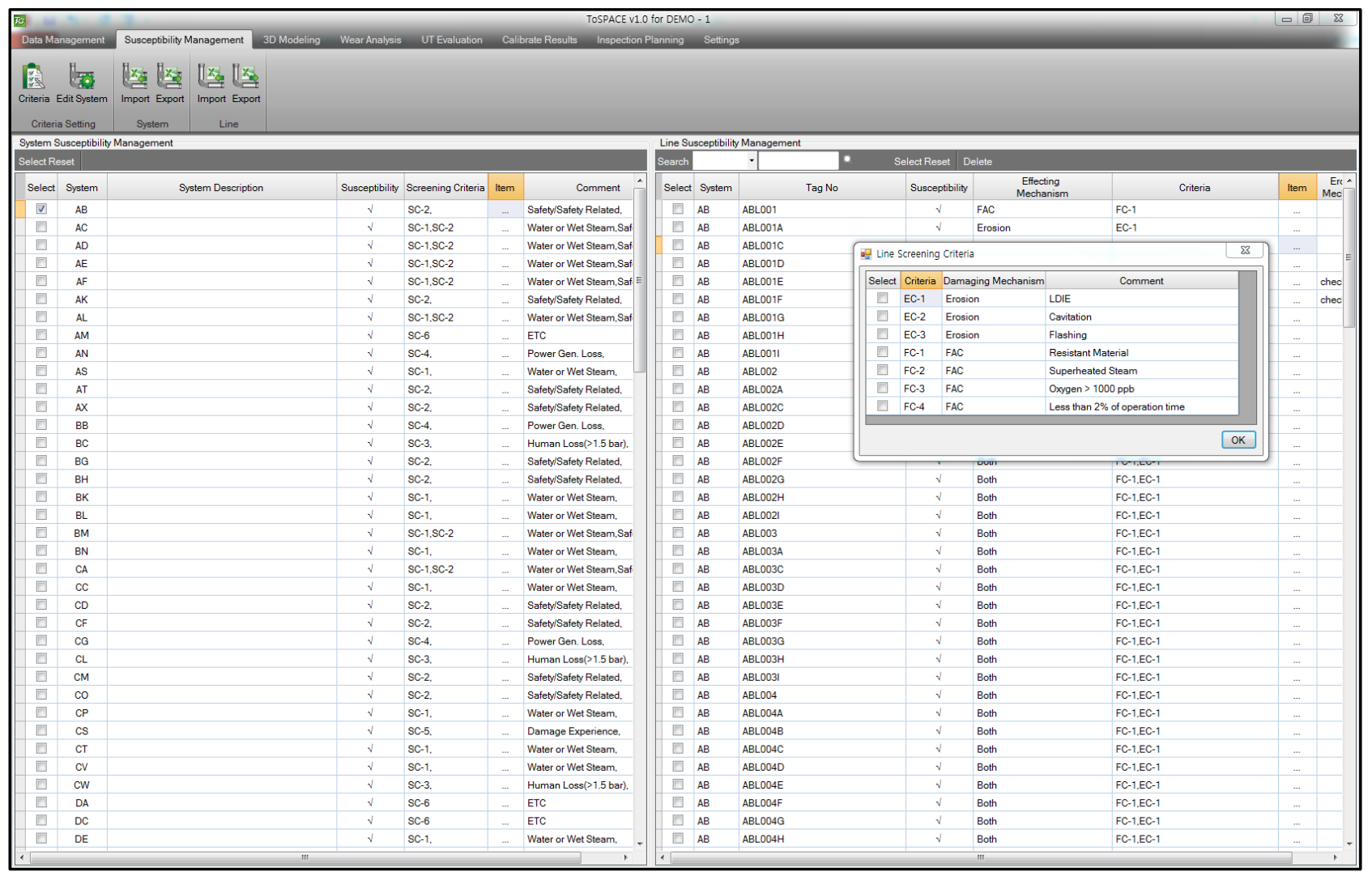

Figure 1. Example of a susceptibility analysis screen. 


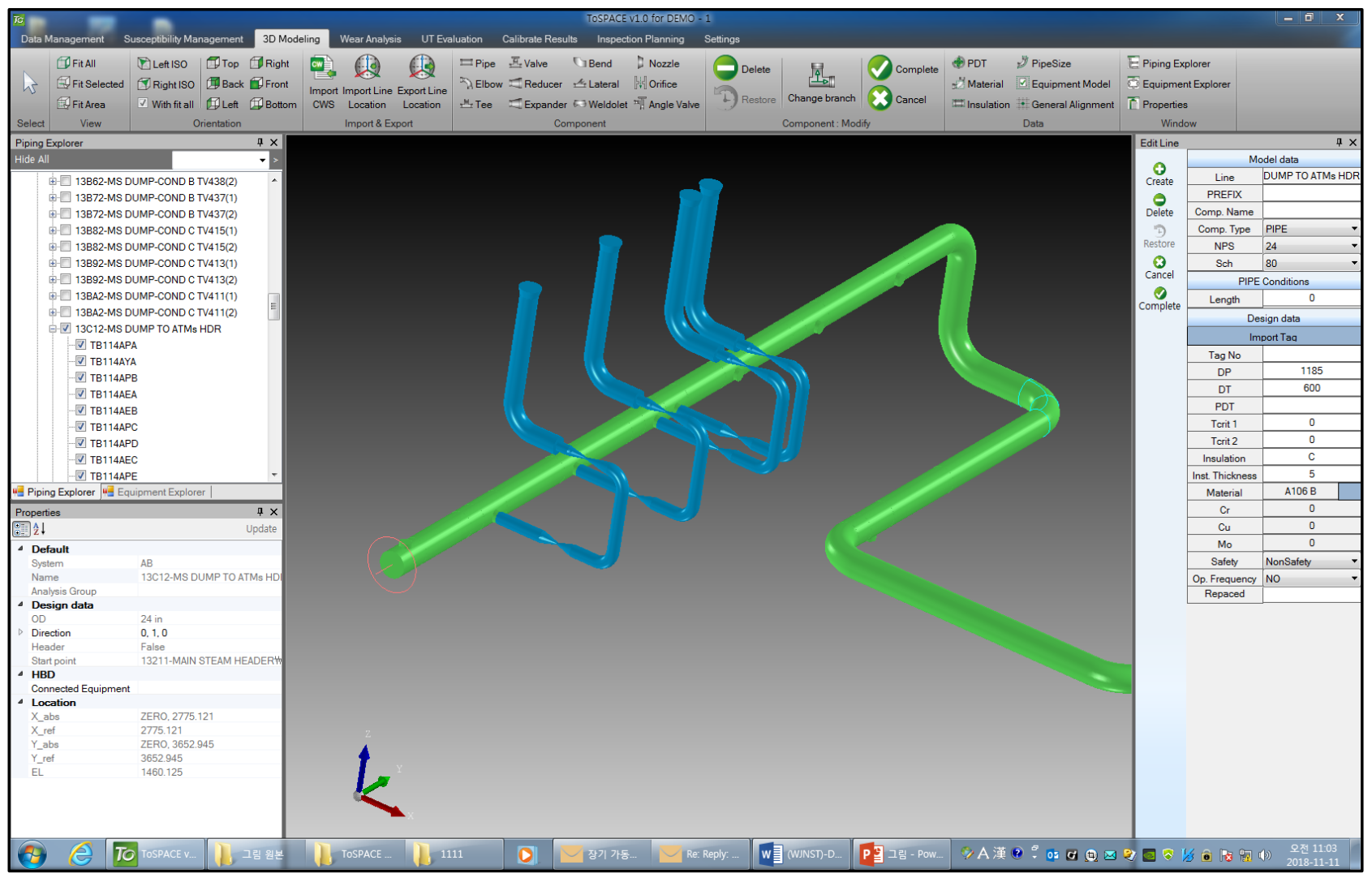

Figure 2. Example of 3D-based database building screen.

and the analysis results should be available as input data for wall thinning analysis such as FAC, LDIE, cavitation, etc.

Accordingly, logic to interpret the thermal-hydraulic characteristics of the single- and two-phase fluid piping and logic to automatically analyze the pipe network (piping layout) were developed. The pipe network analysis logic can maximize the utilization of the program by allowing users to automatically handle the pipe network. Until recently, the users have manually determined the pipe network for thermal-hydraulic analysis in a program. Equations (1) through (4) is the basic formulas for thermal-hydraulic analysis under the condition of single phase fluid [3].

$$
\begin{gathered}
\frac{P_{\text {in }}}{\rho g}+\frac{v_{\text {in }}^{2}}{2 g}+z_{\text {in }}=\frac{P_{\text {out }}}{\rho g}+\frac{v_{\text {out }}^{2}}{2 g}+z_{\text {out }}+h_{L} \\
\dot{m}=\rho A v \\
h_{L}=\left(f \frac{L}{d}+K_{L}\right) \frac{v^{2}}{2 g}, \\
\overline{N u}=\frac{h_{i} d_{i}}{k}=0.023 \operatorname{Re}_{D}^{4 / 5} \operatorname{Pr}^{0.3},
\end{gathered}
$$

where $\dot{m}$ is mass flow rate and $h_{L}$ is head loss. $P, v, g, \rho, f$, and $K_{L}$ denote pressure, flow velocity, gravity acceleration, density, friction factor, and total loss coefficient. 
Equations (5) through (8) are the basic theoretical formulas applied for the thermal-hydraulic calculation under two-phase fluid conditions [4]. Overall pressure drop can be expressed as a sum of pressure drop due to friction, pressure drop due to density difference at inlet and outlet, and pressure drop due to change in locational energy.

$$
\begin{gathered}
\Delta P_{\text {total }}=\Delta P_{\text {frict }}+\Delta P_{\text {acc }}+\Delta P_{\text {static }}, \\
\Delta P_{\text {frict }}=\frac{G^{2}}{2 \rho_{t p}}\left(f_{t p} \frac{L}{d}+K_{\text {total }}\right), \\
\Delta P_{a c c}=G^{2}\left\{\left(\frac{1}{\rho_{t p}}\right)_{\text {out }}-\left(\frac{1}{\rho_{t p}}\right)\right\}, \\
\Delta P_{\text {static }}=\rho_{t p} g z \cdot \sin \theta,
\end{gathered}
$$

where $G$ is mass flux and the remaining parameters are identical to them appleid to single-phase fluids.

\subsection{FAC Prediction Theory}

FAC is a corrosion phenomenon in which the pipe corrosion of carbon steel material is accelerated by fluid flow and is widespread in the secondary side piping of nuclear power plants.

There are several programs that can predict FAC, such as CHECWORKS of USA, BRT-CICERO of France, and COMSY of Germany. FAC prediction theory in CHECWORKS is based on the Chexal-Horowitz equation [5], prediction theory in BRT-CICERO is based on the Sanchez-Caldera equation [6], and FAC prediction theory in COMSY is based on the Kastner-Riedle equation [7].

KEPCO-E \& C has developed a Korea's unique FAC prediction theory based on the existing foreign theories, experimental test data, millions of inspection data accumulated over 20 years, and CFD (Computational Fluid Dynamics) analysis results for numerous cases. Equation (9) is the FAC prediction theory that can be applied to single- and two-phase fluid flow.

$$
\dot{m}_{F A C}=F G\left(v^{b_{1}} D_{i}^{b_{2}} e^{b_{3}+p H} \frac{1}{C r^{b_{4}} C u^{b_{5}} M o^{b_{6}}}\right)
$$

$F, G\left(G_{A}\right.$ of upstream component, $G_{B}$ of downstream component) are shown in Equations (10) and (11). $f(T), f\left(O_{2}\right)$, and $f(Q)$ are the function of temperature, dissolved oxygen, and steam quality. $v$ is flow velocity and $D_{i}$ is inside diameter. $b_{1}$ through $b_{6}, A_{1}, \alpha, t_{1}$, and $y_{0}$ in Equation (12) are constants.

$$
\begin{gathered}
F=f(T) \cdot f\left(O_{2}\right) \cdot f(Q) \\
G_{B}=G_{A}+\frac{G_{A}^{\prime} \cdot g(x)}{10 \cdot y_{0}}, \\
g(x)=A_{1} \times e^{-\left(\frac{\left(\frac{L}{D}\right)+\alpha}{t_{1}}\right)}+y_{0}
\end{gathered}
$$




\subsection{LDIE Prediction Theory}

Liquid droplet impingement erosion (LDIE) is an erosion phenomenon that causes the thickness thinning of pipe wall, due to the impact forces caused by the liquid droplets contained in the steam hitting the wall of pipes or the surface of equipment. The prediction models, that can predict the liquid droplet impingement erosion rate theoretically, are Sanchez-Caldera model [8] presented by MIT (Massachusetts Institute of Technology), Heymann model [9] presented by Westinghouse Co., etc. However, none of the models presented above accurately relates to the magnetite $\left(\mathrm{Fe}_{3} \mathrm{O}_{4}\right)$ formed on the pipe wall and the liquid film flowing on the magnetite.

Accordingly, KEPCO-E \& C has developed a new theoretical formula based on the existing documents, experimental test data, and CFD analysis results for numerous cases, which can be applied to the secondary side piping environment in nuclear power plants [10] [11]. Equation (13) indicates the initiation stage before erosion occurs and Equation (14) indicates the stabilization stage during which erosion occurs at the same time as magnetite dissolving.

$$
\begin{gathered}
\dot{m}_{i}=C_{0} \cdot\left(m_{d} \cdot v_{d}^{2}\right)^{\alpha} \cdot N_{d} \cdot S_{m} \cdot f(A C), \\
\dot{m}_{L D I E}=C_{1} \cdot m_{d} \cdot v_{d}^{2} \cdot N_{d} \cdot f(H v) \cdot f(\theta)+\dot{m}_{i},
\end{gathered}
$$

Each parameter is described as follows:

$\dot{m}_{i}$ : Mass loss rate at initiation stage, $\mathrm{g} / \mathrm{cm}^{2} \cdot \mathrm{h}$

$\dot{m}_{L D I E}$ : Mass loss rate at stabilization stage, $\mathrm{g} / \mathrm{cm}^{2} \cdot \mathrm{h}$

$C_{0}=1.15 \times 10^{-11}$

$C_{1}=1.0 \times 10^{-12}$

$\alpha$ : Constant (0.2)

$m_{d}$ : Mass of a droplet, $\mathrm{g}$

$v_{d}:$ Velocity of droplets, $\mathrm{m} / \mathrm{s}$

$N_{d}$ : Number of droplets

$S_{m}$ : Solubility of magnetite, $\mathrm{g} / \mathrm{m}^{3}$

$f(T)$ : Temperature correction factor

$f(A C)$ : Alloy content correction factor

$f(H v)$ : Vickers hardness correction factor

$f(\theta)$ : Collision angle correction factor

\subsection{SPE Prediction Theory}

Solid particle erosion differs from liquid droplet impingement erosion in that the pipe wall thickness is thinned due to the collision of solid particles, not liquid droplets. Generally, it is easy to think that solid particles do not exist because the systems in nuclear power plants are operated in clean conditions. Due to the feature of operation of the systems such as the steam generator blow down system and raw water recirculation system, it is highly probable that the systems will contain fine solid particles. Solid particles can also be generated by fine particle removal by valve or pump operation and erosion of piping and equipment. 
Although the theoretical models for predicting the solid particle erosion are Ian Finnie model [12], Kosel model [1], etc., they are not enough to be applied to sites such as nuclear power plants. Accordingly, KEPCO-E\&C has developed a new SPE prediction formula based on the experimental test data and CFD analysis results for numerous cases, which can be applied to the secondary side piping environment in nuclear power plants [13].

Equation (15) is applicable to a range between $25^{\circ} \mathrm{C}$ and $95^{\circ} \mathrm{C}$ of fluid temperature and Equation (16) is applicable to a range between $95^{\circ} \mathrm{C}$ and $280^{\circ} \mathrm{C}$ of fluid temperature.

$$
\begin{gathered}
\dot{m}_{S P E}=\frac{\varphi K R A}{\rho t}\left[B+C_{0}(T-25)\right] \cdot 10^{-4}, \\
\dot{m}_{S P E}=\frac{\varphi K R A}{\rho t}\left[B+C_{1}(T-95)\right] \cdot 10^{-4} .
\end{gathered}
$$

where $K$ and $R$ are shown in Equations (17) and (18). $\dot{m}_{S P E}, \varphi, T, \rho, t, \lambda$, and $d_{s}$ are SPE rate $\left(\mathrm{g} / \mathrm{cm}^{2} \cdot \mathrm{h}\right)$, collision angle, temperature, density, operating time, inverse time constant, and particle size. And, $A, B, C_{0}, C_{1}$ are experimental constants.

$$
\begin{gathered}
K=245.71 \cdot \ln (t-\lambda)-165.54, \\
R=0.9277 \cdot \ln \left(d_{s}\right)+3.4038
\end{gathered}
$$

\subsection{UT Data Reliability Analysis Method}

When a nuclear power plant is operated for a long period of time, the thickness of its secondary side piping may gradually become thinner under high temperature and high velocity fluids, and may eventually rupture. To prevent this damage, the utilities periodically measure the thickness of a certain amount of piping and evaluate the thinning conditions, and repair or replace them if necessary. As the UT evaluation methods for assessing the pipe wall thinning state, there are band method, blanket method, point to point method, etc. However, if there is even one error data among the many thickness data about 100 or 250 obtained for each pipe opening, the reliability of the UT evaluation result to determine the next inspection timing and the remaining life may be problematic.

Accordingly, KEPCO-E \& C has developed two UT data reliability analysis methods: SAM (Square Average Method) for one inspection and Multi-SAM methods for over two inspections, which can be applied before performing the UT evaluation [14]. SAM method is to compare one point with the surrounding eight points as shown in Figure 3 and Equation (19).

$$
\alpha x_{(i, j)} \geq \frac{1}{8}\left\{x_{(i-1, j-1)}+x_{(i, j-1)}+\cdots+x_{(i, j+1)}+x_{(i+1, j+1)}\right\},
$$

where $\alpha$ denotes weight factor, $i$ and $j$ are grid coordinates, and $x$ denotes pipe wall thickness at a point.

Multi-SAM method is applied to a component inspected over twice. First, the thickness change rate $\left(x^{\star}\right)$ by inspection timing is calculated and the occurrence 


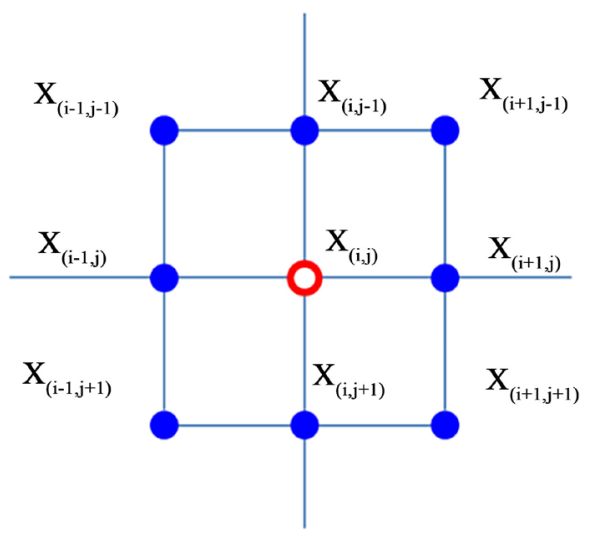

Figure 3. SAM method.

probability of $x^{*}$ is a method of analyzing reliability through three sigma method as shown in Equation (20).

$$
x^{*}=\frac{\left\{\left(T_{\text {cur }}-T_{\text {pre }}\right) / T_{\text {pre }}\right\} \times 100}{\text { Operating Time }},
$$

where $x^{*}$ denotes the thickness change rate (\%/year). $T_{c u r}$ is current inspection thickness and $T_{p r e}$ is previous inspection thickness. Operating time means the time difference between the previous inspection timing and current inspection timing.

\subsection{UT Evaluation Method}

UT evaluation methods are a way to assess the condition of pipe wall thickness. EPRI (Electric Power Research Institute) of the United States suggested several UT evaluation methods such as band method, blanket method, point to point method, etc.

Band method compares the maximum and minimum thicknesses in the circular direction of the inspected pipe with the data measured once. Blanket method compares the maximum and minimum thicknesses among the data set of blanket type with the data measured once. The blanket is then moved to another location on the piping component and the process is repeated. However, the disadvantage of these methods is that they do not reflect its thickness deviation that could exist in the piping from the time of its manufacture. Point to point method is to determine the wear rate at a same point by dividing the differential thickness into the operating time when inspecting the same pipe more than once. This method uses only two inspection data, even though it has been measured several times, and uses a point with a large thickness difference among the total data, so the data for which no thinning occurs can be determined by the typical wear rate of the inspected piping component.

Accordingly, KEPCO-E \& C has developed two UT evaluation methods: E-Cross method applicable to a data set inspected only once and M-PTP method applicable to data sets inspected more than once, which can reflect the manu- 
facturing characteristics of pipe and determine the representative wear rate of an inspected piping component at which the actual thinning occurs. As shown in Table 1 and Equation (21), the wear determined by E-Cross method is the difference between the maximum thickness of the average thickness in rows and columns at minimum thickness and the minimum thickness, except for the total of nine data from $(D, 8)$ to $(F, 10)$ including the smallest of the data and the surrounding eight data in the entire data set.

$$
\text { Wear }=\max (\text { raw avg., column avg. })-t_{\text {min }} \text {. }
$$

To apply the M-PTP Method, all the average values of nine data set from the final inspected data set of a piping component should be calculated and then identified whether the thinnest point is included in the minimum value's grid range of the nine data set. If the thinnest point is included in the minimum value's grid range of the nine data set, the represented wear is determined to be the maximum thickness difference among the nine points. If not, the representative wear is determined by the difference between the thickest value at the minimum value's grid range and the thinnest value among all thickness values of the inspected piping component. This method is to perform the UT evaluation in the area where the actual thinning occurs.

\subsection{D Management}

In operating nuclear power plants, the thicknesses of a given amount of the piping components are inspected for managing piping wall thinning on an overhaul basis. To inspect the pipe wall thickness, the works such as selection of inspecting components, identification of installed location at a site, installation and removal of scaffolding should be performed in advance of UT inspection. To perform these works, it is necessary to identify the exact location of the piping components in a plant and to determine whether the inspections have been performed and the piping components have been repaired or replaced.

Table 1. Application example of E-Cross Method.

\begin{tabular}{cccccccccccccc}
\hline & $\mathrm{A}$ & $\mathrm{B}$ & $\mathrm{C}$ & $\mathrm{D}$ & $\mathrm{E}$ & $\mathrm{F}$ & $\mathrm{G}$ & $\mathrm{H}$ & $\mathrm{I}$ & $\mathrm{J}$ & $\mathrm{K}$ & $\mathrm{L}$ & Avg. \\
\hline 1 & 0.565 & 0.524 & 0.48 & 0.466 & 0.46 & 0.451 & 0.5 & 0.542 & 0.591 & 0.602 & 0.57 & 0.566 & 0.526 \\
2 & 0.574 & 0.539 & 0.51 & 0.454 & 0.417 & 0.453 & 0.477 & 0.530 & 0.585 & 0.61 & 0.588 & 0.579 & 0.526 \\
3 & 0.577 & 0.545 & 0.497 & 0.441 & 0.438 & 0.463 & 0.489 & 0.541 & 0.574 & 0.607 & 0.583 & 0.578 & 0.528 \\
4 & 0.592 & 0.549 & 0.497 & 0.424 & 0.436 & 0.475 & 0.497 & 0.543 & 0.583 & 0.605 & 0.579 & 0.577 & 0.530 \\
5 & 0.583 & 0.551 & 0.507 & 0.433 & 0.447 & 0.472 & 0.506 & 0.540 & 0.593 & 0.601 & 0.547 & 0.573 & 0.529 \\
6 & 0.589 & 0.537 & 0.506 & 0.443 & 0.433 & 0.467 & 0.489 & 0.536 & 0.619 & 0.594 & 0.530 & 0.582 & 0.527 \\
7 & 0.571 & 0.531 & 0.504 & 0.443 & 0.423 & 0.454 & 0.498 & 0.556 & 0.607 & 0.577 & 0.533 & 0.582 & 0.523 \\
8 & 0.565 & 0.530 & 0.495 & 0.432 & 0.412 & 0.454 & 0.500 & 0.560 & 0.607 & 0.582 & 0.556 & 0.586 & 0.553 \\
9 & 0.566 & 0.537 & 0.492 & 0.429 & 0.409 & 0.455 & 0.485 & 0.549 & 0.601 & 0.586 & 0.567 & 0.586 & 0.552 \\
10 & 0.574 & 0.531 & 0.47 & 0.431 & 0.421 & 0.450 & 0.491 & 0.550 & 0.589 & 0.579 & 0.568 & 0.598 & 0.550 \\
11 & 0.575 & 0.533 & 0.447 & 0.437 & 0.443 & 0.453 & 0.495 & 0.532 & 0.575 & 0.575 & 0.563 & 0.598 & 0.519 \\
12 & 0.551 & 0.503 & 0.457 & 0.464 & 0.450 & 0.464 & 0.481 & 0.498 & 0.565 & 0.563 & 0.539 & 0.585 & 0.510 \\
Avg. & 0.574 & 0.534 & 0.489 & 0.445 & 0.439 & 0.461 & 0.492 & 0.540 & 0.591 & 0.590 & 0.560 & 0.583 & \\
\hline
\end{tabular}


Since ToSPACE program was developed on a 3D basis, the installed location and the status of inspection or replacement in the past can be confirmed in three dimensions. Figure 4 shows an example of 3D display included in ToSPACE. The piping components have been developed to work in conjunction with the 3D function, so design and operating information, inspection and replacement information, and thinned status can be easily identified with the naked eyes and work plans in a site can be easily established.

\subsection{Analysis Automation}

In the past, it took a lot of manpower and time to manually designate the type of analytical pipelines and to set various analysis conditions step by step for performing the water chemistry analysis, network flow analysis, and wear rate analysis.

On the contrary, ToSPACE simultaneously performs the several types of analyses, such as chemistry analysis, network flow analysis, and FAC, LDIE, cavitation, and flashing analyses after entering the boundary conditions at the inlet and outlet with the pipeline group to be analyzed on 3D. Accordingly, users can access the program with much convenience and significantly reduce the analysis time. Figure 5 shows an example screen that sets the boundary condition for the wear rate analysis using ToSPACE. Figure 6 shows an example of the wear rate analysis result. On screen, the red color indicates the piping components with high wear rate while the yellow color means the low wear rate components.

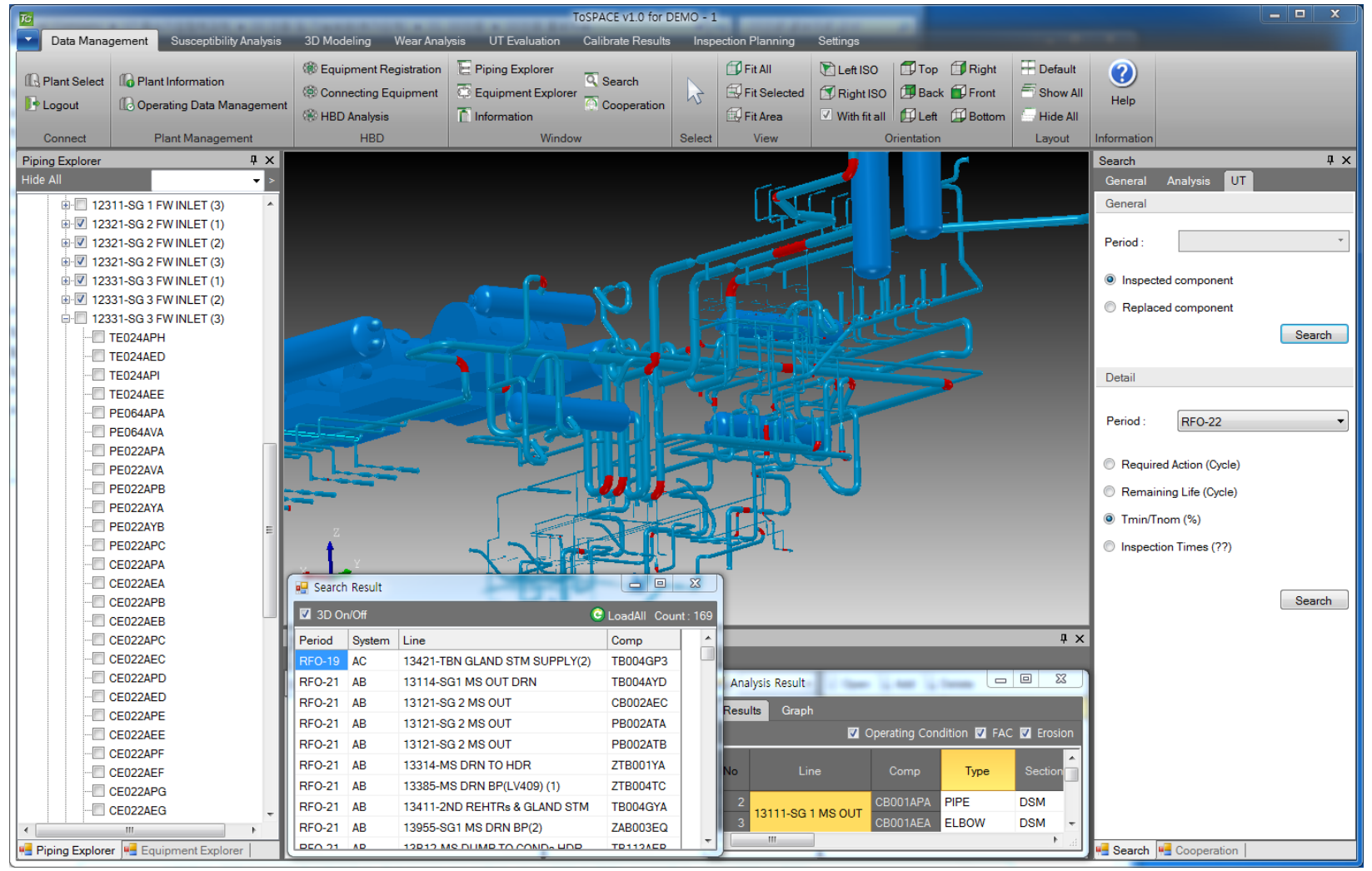

Figure 4. 3D display included in ToSPACE. 


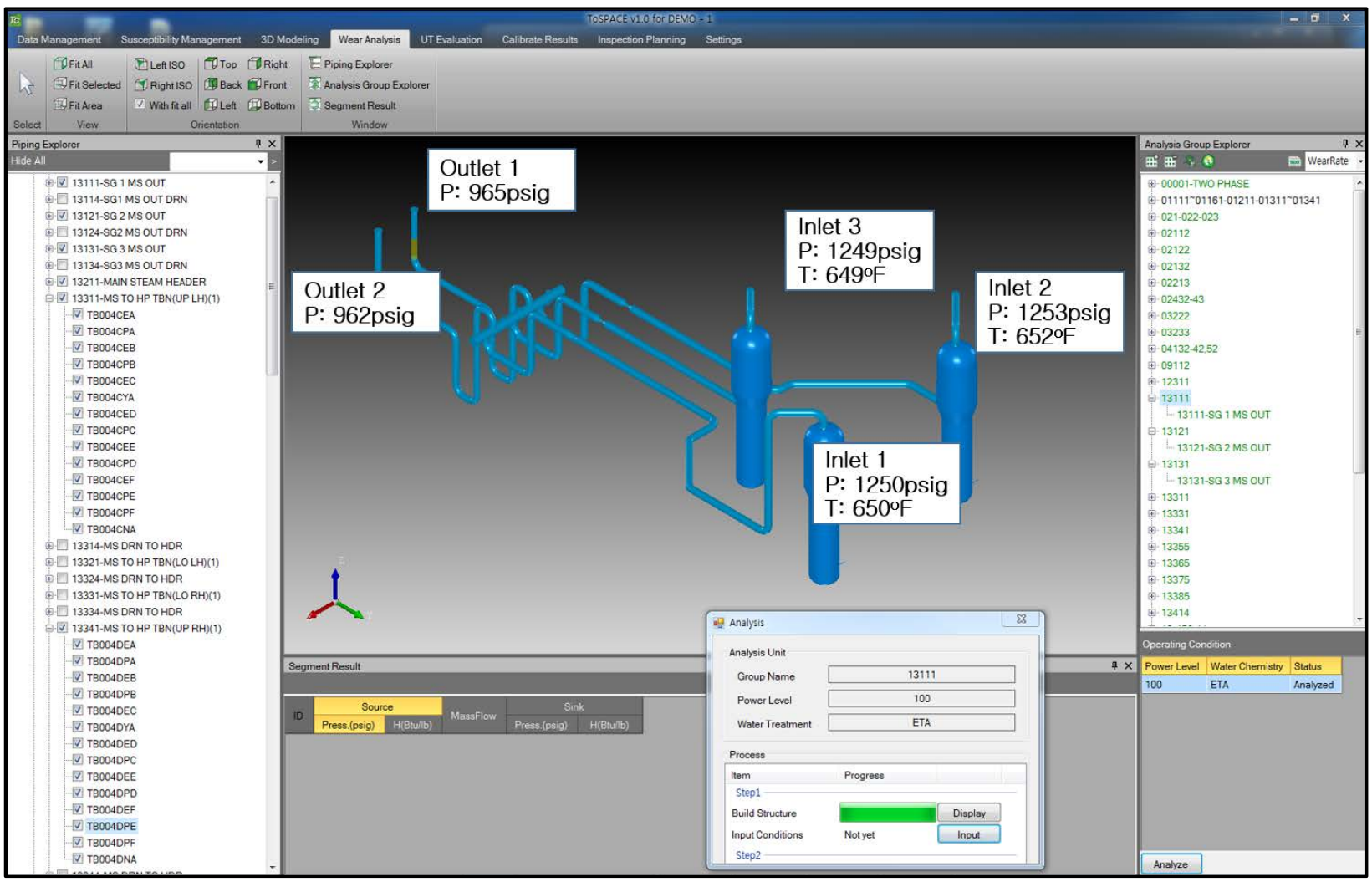

Figure 5. Display for boundary condition setting.

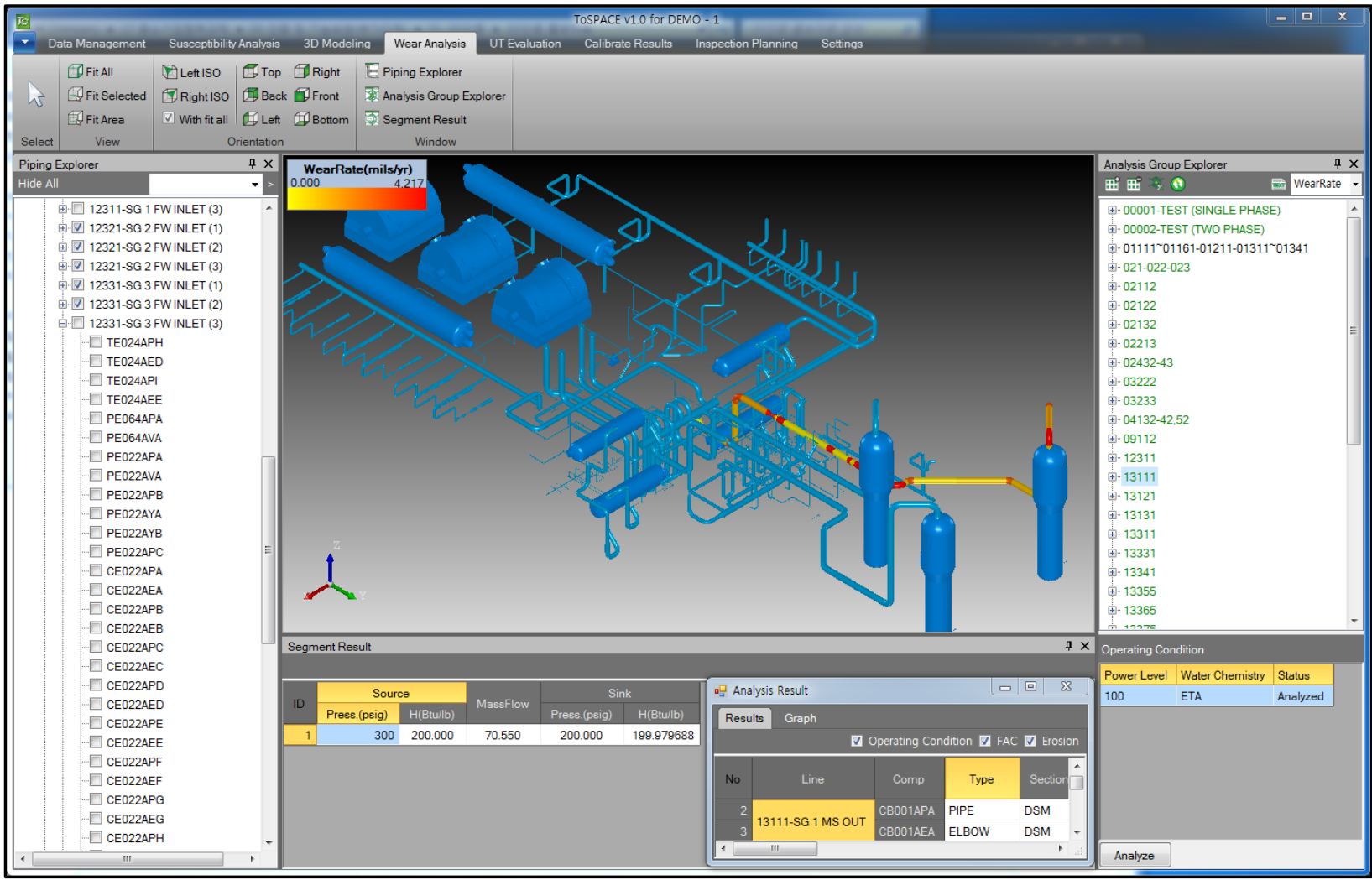

Figure 6. Display of wear rate analysis result. 


\subsection{Automatic LTIP Establishment}

Until now, the site engineers in charge of the pipe wall thinning management have manually established a long-term inspection plan referring to the wear rate analysis result. This was one of the hardest works for site engineers because it took a lot of time requiring a considerable engineering judgment.

Accordingly, the functions establishing the long-term inspection plan (LTIP) and selecting the inspecting components by operating cycle were developed and loaded into ToSPACE program with logic that was clicked or automatically established in the program. The procedure for selecting the inspecting components by operating cycle is as follows:

1) Click manually on $3 \mathrm{D}$ for RC (Regulatory Comment of a regulatory body) locations

2) Click manually on 3D for OE (Other-plant Experience) locations

3) Click manually on 3D for BI (Baseline Inspection) locations

4) Click manually on 3D for EJ (Engineering Judgement) locations

5) Determine automatically within program for UE (UT Evaluation result) locations

6) Determine automatically within program for SIA (Safety Impact Analysis) locations.

Figure 7 shows an example display for the LTIP establishment. The inspecting component determination method based on 6) SIA above is applied to determine newly inspecting components, which determines the target components of inspection based on the results of the risk ranking evaluation by scoring several variables such as nuclear safety, operating frequency, design pressure, design temperature, replacement history, wear evaluation result, UT evaluation result, etc.

The calculation method for selecting inspection components according to SIA method is shown in Equations (22) and (23).

$$
\begin{gathered}
T_{i}=\frac{N_{p} \times A_{i}}{\sum_{i=1}^{k} A_{i}}, \\
A_{i}=N_{p} \times \vartheta \times f_{i} \times \frac{N_{i}-n_{i}}{\sum_{i=1}^{k} B_{i}},
\end{gathered}
$$

where the variables are as follows:

$T_{i}=$ Number of inspecting components

$N_{p}=$ Number of determined components for inspection

$A_{i}=$ Basic value of a pipeline

$i=$ Pipeline number

$k=$ Number of total pipelines

$\vartheta=$ Weighting factor

$f_{i}=$ Factor to reflect inspecting components

$N_{i}=$ Number of components requiring inspection

$n_{i}=$ Number of previously inspected components 


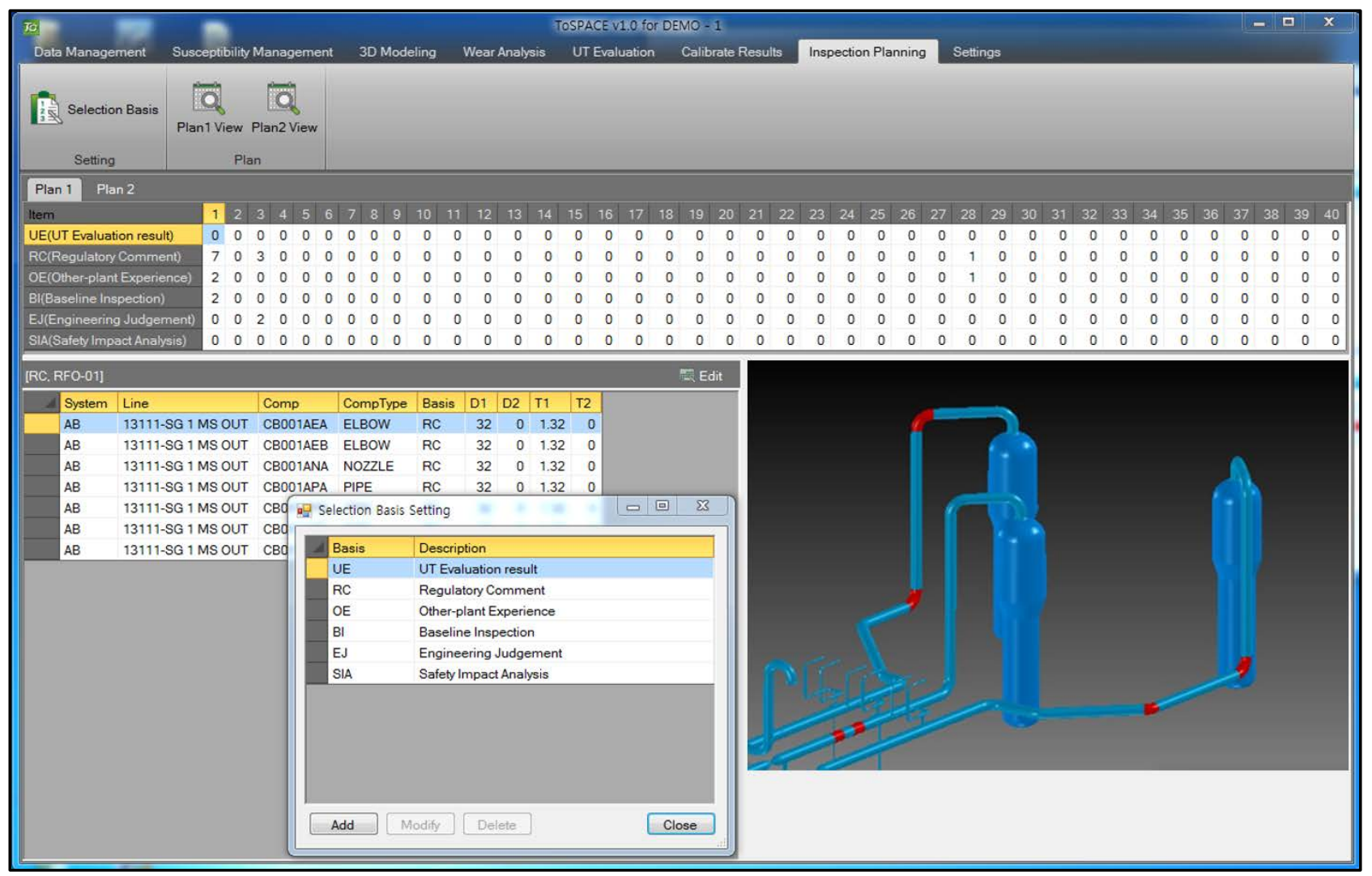

Figure 7. Display for LTIP establishment.

\section{Conclusions}

For the past 30 years, Korea has used overseas program to manage the pipe wall thinning in nuclear power plants. While the maintenance period in nuclear power plants is getting shorter, the use of the existing program was so complex and took a lot of manpower and time. As the needs to develop a new program that is easily accessible and easy to use by engineers on site were raised, KEPCO-E \& C has developed ToSPACE program since 2013.

ToSPACE program allows the site engineers to perform various works, such as susceptibility analysis and selection of inspecting components by operating cycle within the program, and creates a database at the same time as creating a three dimensional drawing. Also, ToSPACE simultaneously performs several types of analysis, such as chemistry analysis, network flow analysis, and FAC, LDIE, cavitation, and flashing analyses after entering the boundary conditions at the inlet and outlet with the pipeline group to be analyzed on 3D. Accordingly, users can access the program with great convenience and significantly reduce the analysis time. The results of wear rate analysis are fed back to the susceptibility analysis and can be automatically reflected in the selection of components to be inspected by operating cycle.

As mentioned above, ToSPACE is a program developed using new concepts that are not implemented by the existing other programs, which can contribute to dramatically reducing the time and effort of the site engineers. 


\section{Conflicts of Interest}

The authors declare no conflicts of interest regarding the publication of this paper.

\section{References}

[1] EPRI (2004) Recommendations for Controlling Cavitation, Flashing, Liquid Droplet Impingement, and Solid Particle Erosion in Nuclear Power Plant Piping Systems. TR-1011231.

[2] Hwang, K.M. (2013) Cause Analysis for the Wall Thinning and Leakage of a Small Bore Piping Downstream of an Orifice. Corrosion Science and Technology, 12, 227-232. https://doi.org/10.14773/cst.2013.12.5.227

[3] Cengel. Y.A. and Cimbala, J.M. (2005) Fluid Mechanics Fundamentals \& Applications. McGraw-Hill, New York.

[4] Idelchik, I.E. (2005) Handbook of Hydraulic Resistance. Jaico Publishing House, Mumbai.

[5] EPRI (2012) CHECWORKS ${ }^{\mathrm{TM}}$ Steam/Feedwater Application (SFA) Version 4.0. TR-1025251.

[6] Qiu, G., Mansour, C. and Trevin, S. (2013) BRT-CICERO ${ }^{\mathrm{TM}}$ Development at EdF: A brief History of Operating Feedback. R\&D Programs and Software Improvement, FAC 2013, Avegnon France.

[7] Kastner, W., Erve, M., Henzel, N. and Stellwag, B. (1990) Calculation Code for Erosion Corrosion Induced Wall Thinning in Piping Systems. Nuclear Engineering and Design, 119, 431-438. https://doi.org/10.1016/0029-5493(90)90182-W

[8] Keck, R.G. and Griffith, P. (1987) Prediction and Mitigation of Erosive-Corrosive Wear in Secondary Piping Systems of Nuclear Power Plants. Massachusetts Institute of Technology, NUREG/CR-5007, 1-15.

[9] Heymann, F.J. (1969) High-Speed Impact between a Liquid Drop and a Solid Surface. Journal of Applied Physics, 40, 5113-5122. https://doi.org/10.1063/1.1657361

[10] Hwang, K.M., Lee, C.G., Bhang, K.J. and Yim, Y.S. (2011) A Study on the Design of a Pipe Affected by Liquid Droplet Impingement Erosion. Journal of Mechanical Science and Technology, B, 35, 1097-1103.

[11] Hwang, K.M., Seo, H.K., Lee, C.K. and Nam, W.C. (2017) Development of a LDIE Prediction Theory in the Condition of Magnetite Formation on Secondary Side Piping in Nuclear Power Plants. World Journal of Nuclear Science and Technology, $B, 7,1-14$. https://doi.org/10.4236/wjnst.2017.71001

[12] Levy, A.V. (1995) Solid Particle Erosion and Erosion-Corrosion of Materials. ASM International, Materials Park, Ohio.

[13] Lee, C.K. (2012) Solid Particle Erosion Analytical Approach for Nuclear Power Plants. Corrosion and Protection, B, 10-11, 26-31.

[14] Yun, H., Hwang, K.M. and Lee, C.K. (2013) Development of Safety Factors for the UT Data Analysis Method in Plant Piping. World Journal of Nuclear Science and Technology, 3, 143-149. https://doi.org/10.4236/wjnst.2013.34024 